\title{
Geodiversidade e análise da paisagem: uma abordagem teórico-metodológica
}

\author{
GEODIVERSITY AND LANDSCAPE ANALYSIS: A THEORETICAL AND METHODOLOGICAL APPROACH
}

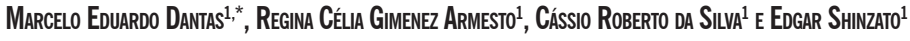 \\ 1 Serviço Geológico do Brasil, CPRM, Depto. Gestão Territorial, DEGET. Av. Pasteur, 404, Urca, 22290-240 Rio de Janeiro RJ. * marcelo.dantas@cprm.gov.br
}

\section{Manuscrito \\ Recebido: $5 / 7 / 2012$ \\ Corrigido: 30/9/2014 \\ Aceito: 9/10/2014}

Citation: Dantas M.E., Armesto R.C.G., Silva C.R., Shinzato E. 2015. Geodiversidade e análise da paisagem: uma abordagem teórico-metodológica. Terræ Didatica, 11(1):04-13. < http://www.ige. unicamp.br/terraedidatica/>.

Keywords: Geodiversity, Landscape Analysis, Environmental Geology, Epistemology.

\begin{abstract}
Geodiversity consists of a new brunch of geosciences. It is derived from the environmental geology and it aims to proceed a whole study of the abiotic system that includes rocks, saprolite, landforms and soils. The research development in geodiversity starts in the last decade of twentieth century. It has generated encouraging results in geoconservation and territorial management studies in Brazil and all over the world. However, towards the consolidation of the landscape concept, so important to geography science, it is necessary to improve the geodiversity studies and techniques based on a multidisciplinary approach. This article proceeds to an epistemological evaluation of the concept of landscape and its theoretical and methodological importance for developing environmental geology and geodiversity studies. These guidelines accomplish the mission of CPRM - the Brazilian Geological Survey for geodiversity mapping of the whole Brazilian territory.
\end{abstract}

\section{Paisagem: definição e formalização de um conceito}

As paisagens que são reconhecidas pelo observador em qualquer porção do Espaço Geográfico congregam um conjunto de elementos do meio geobiofísico (rochas, minerais, relevo, solos, biota) em dinâmica transformação por processos geológicos, hidrológicos e atmosféricos. Do mesmo modo, essas paisagens são continuamente transformadas pela ação humana no Espaço Geográfico, atividade essa cada vez mais intensa à medida que a Sociedade se torna mais tecnificada (Santos 2000). Deste modo, não se pode mais preconizar a existência de paisagens naturais, pois todas apresentam, em maior ou menor grau, a interferência antropogênica.

A origem das paisagens, por sua vez, pode ser analisada, com relação ao seu substrato (ou meio abiótico) pela atuação combinada de processos endógenos (tectônica; vulcanismo; sismicidade) que promovem a geração de massa rochosa e relevos positivos ou negativos; e processos exógenos (intemperismo; erosão; sedimentação) que pro- movem a esculturação e o arrasamento das massas rochosas anteriormente geradas.

No entanto, o conceito de Paisagem é usualmente aplicado de forma bastante ampla e vaga pelos mais diversos campos do conhecimento geocientífico ou por distintas atividades profissionais não diretamente relacionadas ao campo das Geociências, tais como o Turismo, a Arquitetura, as Artes e a Biologia, dentre muitas outras. Este conceito é também vastamente utilizado por um amplo espectro de profissionais que estudam as questões vinculadas à gestão ambiental ou ao planejamento territorial em seus diversos níveis, escalas e recortes temáticos de análise.

Portanto, é bastante compreensível que o conceito de Paisagem seja bastante fluido com interpretações até mesmo díspares, conforme sua aplicação e a formação teórico-acadêmica de quem o utiliza. Neste sentido é necessário, em primeiro lugar, definir e formalizar este conceito para que, a partir de então, este possa ser analisado, sem querelas de ordem etimológica ou epistemológica, no contexto da Geodiversidade. 
Sendo assim, o conceito de Paisagem consiste numa das categorias de análise mais relevantes no âmbito da ciência geográfica (em conjunto com os termos Espaço, Região, Território e Lugar) (Corrêa 1995). Trata-se, portanto, de um conceito caro à Geografia e que vem sendo sistematicamente discutido e aprimorado desde o século XIX. Desta forma, opta-se por formalizar e consolidar este conceito com base no rico e duradouro debate praticado durante muitas décadas no seio da ciência geográfica.

Etimologicamente, o conceito de Paisagem deriva do vocábulo paysage, de origem francesa. Similar e contemporâneo ao termo alemão landschaft , o vocábulo paysage originou-se nos séculos XV e XVI, em fins da Idade Média e tinha claro significado espacial e delimitado, representando um recorte geográfico de uma determinada área ocupada por restritas aglomerações humanas e seus arredores (Maximiano 2004). Este vocábulo tem sua gênese fortemente associada ao Modo-de-Produção Feudal com uma sociedade rural, tradicional e estática e com uma estrutura espacial pulverizada em burgos e feudos, onde cada feudo é politicamente autônomo e economicamente auto-suficiente ${ }^{1}$. O termo alemão landschaft, por sua vez, está mais diretamente associado ao conceito de paisagem natural, diferenciando-se do conceito de paisagem geográfica ou paisagem cultural, pois não é considerado o processo de transformação social da paisagem natural pela atividade humana.

Apenas no século XIX, o conceito de Paisagem é formalmente estabelecido, ainda que sem a devida solidez, nos primórdios da ciência geográfica. Assim, a Paisagem foi modernamente definida como a dimensão perceptível (panorama) de um determinado Espaço Geográfico abarcando, de forma entrelaçada, os aspectos naturais e culturais (Sauer 1998, dentre muitos outros). Neste sentido, o conceito de Paisagem apresenta uma marcante conotação empírica, resultante da observação de um determinado pesquisador sobre a fisionomia de uma região a partir dos aspectos visíveis. Posteriormente, o conceito é aprimorado adicionando a este, a análise dos processos naturais e das relações sócio-econômicas (não-visíveis) conferindo, assim, uma dinamicidade ao conceito de Paisagem.

Portanto, pode-se ressaltar que a paisagem é um conceito de abrangência multidisciplinar e uma poderosa ferramenta de análise espacial.

1 A origem etimológica do vocábulo paysage deriva, portanto, de seu contexto histórico de uma sociedade feudal, onde um feudo estaria associado a um pequeno país - pays e sua abrangência espacial, ou o panorama visível ao observador, seria denominado de paysage.

\section{Origem e desenvolvimento do conceito de paisagem: breve discussão}

O conceito de Paisagem é sistematizado entre fins do século XVIII e início do século XIX pelo naturalista alemão Alexander von Humboldt, considerado também o sistematizador da Geografia, enquanto campo autônomo do conhecimento científico. Humboldt foi um dos mais relevantes sábios naturalistas de seu tempo, sendo dotado de vasto espectro de conhecimento que abarcava desde a Geologia até a Botânica e utilizou o conceito de Paisagem Natural - landschaft - como elemento integrador de todas as variáveis naturais que compunham o meio geobiofísico. A Escola Naturalista Alemã, sob uma ótica estética e romântica, relatava uma sensação de prazer estético proporcionado pela percepção da fisionomia da paisagem, seu objeto de estudo (Salgueiro 2001). Em termos de método, Humboldt calcou seus estudos na observação integrada dos elementos da paisagem natural, aplicada em sua famosa viagem pela América Espanhola ${ }^{2}$, tendo sido denominada de "Empirismo Raciocinado" (Moraes 1984). Assim, o emprego científico do conceito de Paisagem, na condição de categoria de análise espacial, nasce simultaneamente com a própria ciência geográfica.

Todavia, a Escola Francesa de Geografia, posterior à Escola Alemã, tendo sido consolidada apenas a partir de 1870, desenvolve sua vertente Possibilista consagrada por Paul Vidal de La Blache e apresenta uma análise diferenciada do conceito de Paisagem - paysage - na qual se destaca uma visão integrada não apenas dos aspectos naturais, mas de uma correlação espacial entre os elementos naturais e humanos sobre o terreno - a paisagem geográfica, seguindo uma abordagem já iniciada por Karl Ritter na Alemanha de meados do século XIX. Desta forma, a Geografia Francesa humanizou o conceito de Paisagem, atribuindo-lhe uma forte carga histórica, ou seja, a paisagem geográfica, objeto de estudo das análises empíricas, é resultante histórica do trabalho que diferentes sociedades e

2 Alexander von Humboldt, com permissão da Coroa Espanhola, empreendeu uma importante viagem à América do Sul e Central entre 1799 e 1804. Este naturalista descreveu e coletou um valioso acervo de amostras de plantas e minerais; assim como revelou a interconexão entre as bacias dos rios Negro e Orenoco, na Venezuela; escalou o pico Chimborazo nos Andes Equatorianos, promovendo estudos de zonação bioclimática; destacou o papel das correntes marítimas, sendo que a corrente fria do Pacífico Oriental recebeu seu nome (corrente de Humboldt); analisou o sistema escravocrata de produção de açúcar em Cuba, dentre as mais importantes pesquisas. 0 conjunto de seus estudos foi reunido na monumental obra "Kosmos", publicação que norteou o desenvolvimento da Geografia e das Ciências Naturais durante todo o século XIX. 
"gêneros de vida" desenvolveram sobre o Espaço Geográfico. Neste sentido, o conceito de Paisagem-Região, refere-se a cada porção do Espaço Geográfico produzida por uma peculiar interação entre as características intrínsecas da paisagem natural e atuação transformadora decorrente das atividades humanas. O conceito de Paisagem-Região consagrou a abordagem empírica na Geografia e consiste num instrumento teórico-metodológico de reconhecimento e exploração de todas as regiões do Mundo até meados do século XX, porém tornou-se um conceito-obstáculo na avaliação de Lacoste (1976), pois confinou o conceito de Paisagem a uma abordagem excessivamente empírica e naturalista que, por um lado, mascarava as contradições sociais inerentes ao Espaço Geográfico produzido no Modo-de-Produção Capitalista, e por outro, revelava-se num instrumento ineficaz para o planejamento territorial. A título de ilustração, interessantes compêndios sobre os estudos das paisagens produzidos sob o signo da Geografia Francesa podem ser encontrados em La Blache (apud Lacoste 1976), Monbeig (1984) e Rougerie (1971) que representam algumas gerações de geógrafos que realizaram exaustivas e minuciosas descrições dos aspectos físicos e humanos das paisagens da França, do Brasil e de todo o Mundo.

\section{0 conceito de paisagem como instrumento de planejamento territorial}

A partir da constatação do esgotamento teórico-metodológico da Geografia Tradicional sob a égide do Positivismo Clássico, após o desfecho da $2^{\text {a }}$ Guerra Mundial e com a emergência da Teoria dos Sistemas nos anos 50 pelos diversos campos do conhecimento científico, o conceito de paisagem deixa de ser abordado exclusivamente pelo método empírico e passa a ser apreendido como um sistema natural, ou um Geossistema sob a égide do Positivismo Lógico. Deriva-se desta ruptura epistemológica, três escolas de análise sistêmica da paisagem: as vertentes Russo-Soviética; Francesa; e Alemã.

A vertente russo-soviética, sob influência filosófica do Materialismo Dialético, buscou proceder a uma análise integrada em sua totalidade da paisagem natural calcada na concepção de Unidade Natural Territorial proposta por Dokoutchaev (Rodriguez e Silva 2002, Maximiano 2004). Este esforço metodológico coadunava com a necessidade premente do Estado Soviético de empreender os projetos de planejamento territorial articulados a sua economia planificada e centralizada. Todavia, desastres ambientais decorrentes de planejamentos ambientais equivocados foram produzidos, em especial, os projetos de irrigação na Ásia Central, mais especificamente nas bacias endorreicas dos rios Amur-Daria e Sir-Daria, que promoveram o desaparecimento de grande parte do espelho d'água do Mar Aral (Haesbaert 1998).

Neste contexto, foi Victor Sotchava que formulou, pela primeira vez, a Teoria dos Geossistemas (Sotchava 1960), já sob influência direta da Teoria Geral dos Sistemas, que consistiu numa análise estrutural, hierarquizada e sistêmica da paisagem por meio da superposição e interação das diversas "layers" que compõem o sistema geobiofísico. Tendo em vista que a área de estudo de Sotchava consistia nas imensas planícies siberianas, a análise geossistêmica russa ressaltava um zoneamento biogeográfico.

A vertente francesa, paralelamente à escola soviética, também gerou uma metodologia de análise e classificação de paisagens em base geossistêmica (Bertrand 1972). Todavia, ao contrário do desenvolvimento dos Geossistemas na Rússia, a área de estudo sob enfoque de George Bertrand eram os terrenos acidentados dos Pirineus Franceses, o que motivou uma análise dos Geossistemas priorizando uma compartimentação geológico-geomorfológica.

A abordagem dos Geossistemas na França calcava-se, entretanto, num tripé que abrangia os elementos físicos ou abióticos; os elementos bióticos e elementos antrópicos. Segundo Bertrand, a paisagem deve ser compreendida como interação dinâmica e instável entre esses três elementos do tripé, estando em contínua evolução (Fig. 1). Desta forma, a vertente francesa busca não privilegiar a esfera natural em detrimento da esfera social (Schier 2003).

Uma importante variante da Escola francesa

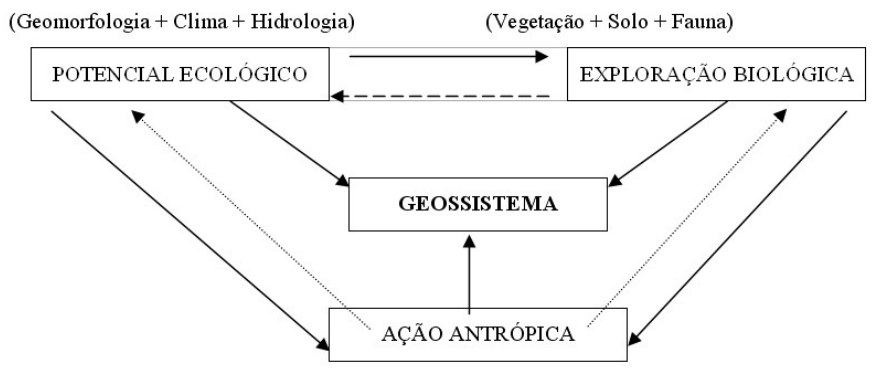

Figura 1. Esquema teórico da abordagem geossistêmica, segundo o modelo em tripé proposto por Bertrand (1972). 
foi desenvolvida por Tricart (1977) com os Estudos de Ecodinâmica e Ecogeografia que enfatizava uma análise da estrutura da paisagem em sua morfodinâmica sem preocupação em delimitar unidades territoriais singulares. Assim, numa abordagem claramente geomorfológica, Jean Tricart classificava distintas paisagens conforme sua fragilidade ambiental enfatizando sua vulnerabilidade aos processos erosivo-deposicionais e destacando áreas onde predominam a morfogênese ou áreas onde predomina a pedogênese.

A vertente alemã, herdeira direta da Escola Naturalista de Humboldt, apóia-se no conceito de paisagem natural (landschaft) acoplados aos Estudos de Ecologia e no conceito de Ecossistema. Deste modo, desenvolve-se uma proposta de análise sistêmica da paisagem e das atividades humanas por meio de uma dinâmica de fluxos e redes de matéria e energia. Esta vertente, inaugurada por Karl Troll desde 1939 (Troll 1966) foi denominada de Geoecologia. Esta vertente alemã foi, posteriormente, desenvolvida por geógrafos americanos e holandeses (destacando as obras fundamentais de Klink 1974, Forman 1995 e Zonneveld 1989, dentre outros) que forjaram o termo - Landscape Ecology - (Ecologia da Paisagem) e reforçaram o caráter naturalista do estudo da Paisagem. Neste contexto, a paisagem natural era entendida como um produto de integrado das variáveis ambientais (geologia; geomorfologia; pedologia; climatologia; biogeografia) e a resultante espacial e mapeável dessa análise integrada seria o Ecótono ou a Unidade de Paisagem (Land Unit).

Neste sentido, a Unidade de Paisagem consiste de uma unidade espacial que apresenta características singulares (tanto no meio geobiofísico, quanto no meio sócio-econômico) que a definem, a delimitam e a distinguem das outras unidades que, por sua vez, estaria em constante dinâmica promovida pela atuação de processos naturais do próprio sistema geobiofísico e pela ação transformadora das atividades sócio-econômicas (Zonneveld 1989). Desta forma, os estudos de impactos ambientais e de gestão territorial poderiam se apropriar desta nova ferramenta de análise que irá depender bastante do desenvolvimento metodológico que evolui, de um lado, segundo ao progresso da sua componente técnica e, do outro, de acordo com os avanços dos estudos do espaço geográfico.

Coelho Netto (1992), seguindo a vertente geoecológica, ressalta a importância dos estudos de Hidrologia na análise integrada do meio geobiofísi- co onde, em ambiente tropical úmido, a água seria "o motor do Geoecossistema", pois promove o intemperismo das rochas; a pedogênese e a erosão dos solos; a esculturação do relevo; e condiciona a distribuição espacial dos distintos biomas.

A Escola Crítica da Geografia de inspiração marxista, vigente a partir dos anos 70, teceu críticas ácidas a respeito da visão naturalista de paisagem desenvolvida pelos estudos de Geoecologia e dos Geossistemas, na qual a ação humana estaria reduzida a um mero "efeito antrópico", menosprezando assim, a importância das atividades humanas e das relações sociais na constituição da paisagem geográfica. Segundo esses autores, dos quais se destaca Milton Santos, a dinâmica sócio-econômica em sua lógica contraditória de uma sociedade de classes deve ser o principal foco de análise do geógrafo.

Monteiro (2001), em sua primorosa autobiografia acadêmica com especial ênfase sobre os Geossistemas, forja o conceito de "Derivações Antropogênicas" para aproximar às análises do meio geobiofísico, as implicações de natureza sócio-econômica impostas à paisagem geográfica. Neste sentido, este autor busca dirimir os problemas causados pela insolúvel dicotomia entre Geografia Física e Humana no contexto dos estudos de avaliações de impacto ambiental e de gestão territorial.

\section{0 conceito de paisagem aplicado a estudos de geodiversidade}

A comunidade geológica ingressa neste rico debate a partir da década de $80 \mathrm{com}$ a necessidade de aproximar a Geologia às demandas da sociedade, com a emergência dos estudos vinculados à Geologia Ambiental. A partir desse momento, o conceito de paisagem passa a ser utilizado nas análises geológicas voltadas para estudos ambientais, incorporando conceitos fundamentais como os de Exaustão dos Recursos Naturais e de Ética e Sustentabilidade Ambiental (Keller 1996, Cordani 2000).

No que tange à demarcação do campo de atuação da denominada Geologia Ambiental, esta congrega todas as aplicações da ciência geológica, num enfoque sistêmico (o Sistema Terra), aos estudos de gestão ambiental e planejamento territorial (CPRM 1994, Dorothy 1997, Cordani 2000, CPRM 2007, Silva e Dantas 2010). Neste sentido, a Geologia revelou-se uma ciência profícua e de múltiplas aplicações, principalmente no que concerne ao desenvolvimento de alguns campos específicos do conhecimento geológico tais como a Geologia 
de Engenharia, a Hidrogeologia, a Geoquímica Ambiental e Geologia Médica, a Geologia do Quaternário e a Neotectônica, dentre outros.

Portanto, dentre as múltiplas contribuições do profissional em Geologia nas esferas social, econômica e ambiental, destacam-se as seguintes: a análise de desastres naturais (deslizamentos, inundações, abalos sísmicos, colapso de terrenos etc.) em áreas de risco geológico; disponibilização e preservação de água subterrânea oriunda de aquíferos livres e confinados para abastecimento humano, industrial e irrigação; a investigação de fatores que comprometem a saúde pública decorrentes do excesso ou carência de determinados elementos químicos seja devido a causas naturais (intemperismo do substrato rochoso), seja devido a razões antrópicas (poluição doméstica ou industrial); e, por fim, a aplicação dos estudos do meio físico "latu sensu" para subsidiar políticas de uso e ordenamento do território (Keller 1996, Bennett e Doyle 1997, Corrêa e Ramos 1995, Dantas et al. 2000, CPRM 2007).

Todavia, a Geologia demonstrou um interesse especial numa análise segmentada da paisagem geográfica que desembocaria no estudo da paisagem do meio físico ou, segundo alguns autores, da paisagem geomorfológica. Este fato aproximou geólogos, geomorfólogos, pedólogos e "geógrafos físicos" em busca de uma análise integrada do meio físico incorporando, inclusive, metodologias já desenvolvidas nas análises de Geoecologia e de Geossistemas.

A paisagem geomorfológica foi definida por Coelho Netto (1992) e Dantas e Coelho Netto (1995) como a resultante espacial da interação das diversas variáveis do meio geobiofísico (relevo-rocha-solo-vegetação-fauna-uso) que regula a distribuição das águas pluviais no domínio das encostas e, consequentemente, a dinâmica dos processos geomorfológicos (intemperismo, erosão e deposição) em diferentes escalas espaço-temporais. Estes autores, inspirados numa abordagem geoecológica, analisaram as mudanças de usos decorrentes da substituição da Mata Atlântica pelo incremento da pressão urbana no Maciço da Tijuca e pela introdução da monocultura cafeeira no Vale do Paraíba do Sul e destacaram a análise da paisagem geomorfológica como um instrumento de gestão ambiental e planejamento territorial.

Apesar da configuração morfológica dos terrenos ser resultante de um balanço entre os processos endógenos (estes comandados pela dinâmica do geodínamo no Planeta - Press et al. 2006) e os processos exógenos (estes comandados pela dinâmica climática, por intermédio da ação dos diversos agentes erosivos - Selby 1985, dentre muitos outros), a Geologia destacou o estudo dos processos endógenos na constituição da paisagem geomorfológica, conforme muito bem sintetizado por Penha (1994).

Neste sentido, a ciência geológica ressaltou a importância do substrato rochoso na constituição do relevo graças ao papel exercido pela Tectônica de Placas, via processos de orogênese e epirogênese, gerando sismos e vulcanismo ou oriunda dos condicionantes litoestruturais. Os condicionantes litoestruturais podem ser expressos de forma ativa ou passiva. Os condicionantes litoestruturais ativos estariam representados pela ação da Neotectônica. Já os condicionantes litoestruturais passivos estariam representados pela resistência diferencial dos materiais constituintes das rochas e ocorrência de planos de fraqueza (diáclases, falhas, planos de foliação) do substrato rochoso na esculturação diferencial do relevo.

Todavia, a partir da elaboração do conceito de Geodiversidade, as Geociências desenvolveram um novo e eficaz instrumento de análise da paisagem de forma integral utilizando o conhecimento do meio físico a serviço da preservação do meio natural e do planejamento territorial, podendo assim, avaliar os impactos decorrentes da implantação das distintas atividades econômicas sobre o espaço geográfico.

O conceito de Geodiversidade é relativamente novo, tendo sido formulado a partir da década de 1990 e consolidado apenas nos últimos anos. $\mathrm{Na}$ literatura internacional, a Geodiversidade tem sido aplicada com maior ênfase aos estudos de Geoconservação. Neste sentido, destacam-se os estudos destinados à preservação do patrimônio natural, tais como: monumentos geológicos, paisagens naturais, sítios paleontológicos, geossítios e geoparques etc.

Inicialmente, pesquisadores ingleses e australianos, tais como Sharples (1993), Duff (1994) e Eberhard (1997) introduzem o conceito de Geodiversidade com este viés, intrinsecamente associado à Geologia e à Conservação Natural, restringindo assim, o conceito Geodiversidade à diversidade geológica dos terrenos.

Gray $(2004,2005)$ consagra o conceito de Geodiversidade abrangendo o sistema abiótico em sua integridade, caracterizando-o como "a diversidade natural entre aspectos geológicos, do relevo e dos solos". Cada cenário da diversidade natural (ou paisagem 
natural) estaria em constante dinâmica através da atuação de processos de natureza geológica, biológica, hidrológica e atmosférica. Um expressivo número de autores (dentre os quais, Sharples 2002, Kozlowski 2004, Brilha 2005, Serrano e Ruiz-Flano 2007, Petrisor e Sarbu 2010), sob diferentes olhares, estendem sua aplicação aos estudos de planejamento territorial, ainda que com uma ênfase destinada a Geoconservação, além de abranger, em certa medida, também sua componente biótica, ou seja, a biodiversidade.

Outros autores, tais como Panizza (2001), Pereira (2005) e Claudino-Sales (2010) enfatizam a correlação entre paisagem e geoconservação na análise do patrimônio geomorfológico e na definição dos geomorfossítios, como elementos integrantes de programas de Geoparques.

Stanley (2001), por sua vez, apresenta uma concepção mais ampla para o termo Geodiversidade, onde as paisagens naturais, entendidas aqui como a variedade de ambientes e processos geológicos, estariam relacionadas com seu povo e sua cultura. Deste modo, este autor estabelece uma interação entre a diversidade natural dos terrenos (compreendida como uma combinação de rochas, minerais, relevo e solos) e a sociedade, numa aproximação com o clássico conceito LaBlacheano de "gênero de vida".

Veiga (1999), por sua vez, enfatiza o estudo das águas superficiais e subterrâneas nos estudos de Geodiversidade. Para este autor, a Geodiversidade "expressa as particularidades do meio físico, compreendendo as rochas, o relevo, o clima, os solos e as águas, subterrâneas e superficiais e condiciona a morfologia da paisagem e a diversidade biológica e cultural”. Brilha (2005) ressalta que ressalta que a Geodiversidade constitui o suporte essencial para o desenvolvimento da Biodiversidade. O estudo da Geodiversidade é, na visão destes autores, uma ferramenta imprescindível de gestão ambiental e norteadora das atividades econômicas.

No Brasil, o conceito de Geodiversidade é desenvolvido praticamente de forma simultânea, porém ressaltando um caráter mais aplicado ao planejamento territorial, ainda que os estudos voltados para a Geoconservação não sejam desconsiderados. Xavier da Silva e Carvalho Filho (2001) definem Geodiversidade a partir da "variabilidade das características ambientais de uma determinada área geográfica" cabendo ao pesquisador, com base em um estudo sistemático de enorme massa de dados ambientais disponíveis em Base de Dados Georreferenciada, a seleção das variáveis que melhor determinam a
Geodiversidade em cada local.

Com base nas proposições apresentadas anteriormente, a CPRM - Serviço Geológico do Brasil define a Geodiversidade como "o estudo da natureza abiótica (meio físico) constituída por uma variedade de ambientes, fenômenos e processos geológicos que dão origem às paisagens, rochas, minerais, fósseis, solos, águas e outros depósitos superficiais que propiciam o desenvolvimento da vida na Terra, tendo como valores intrínsecos a cultura, o estético, o econômico, o científico, o educativo e o turístico" (Silva et al. 2008a).

Em síntese, pode-se considerar que o conceito de Geodiversidade abrange a porção abiótica do Geossistema ${ }^{3}$. Esse reducionismo permite, entretanto, ressaltar os fenômenos geológicos em estudos integrados de gestão ambiental e planejamento territorial. Um notável exemplo da aplicação dos estudos de Geodiversidade pode ser encontrado em CPRM (2007) e em trabalhos posteriores dedicados ao estudo da Geodiversidade de cada estado brasileiro, citando como exemplo, Maia e Marmos (2010), dentre outros.

\section{A paisagem e a geodiversidade brasileira: nova abordagem proposta pelo Serviço Geológico do Brasil}

De acordo com a proposição metodológica formulada pelo Serviço Geológico do Brasil, ao se proceder a um estudo de Geodiversidade, as diversas variáveis do meio abiótico que constituem a paisagem do meio físico devem ser analisadas de acordo com um conjunto de parâmetros, conforme relacionados a seguir:

- a Geologia deve ser analisada de acordo com: a gênese das rochas; a similaridade das unidades litológicas; a composição mineralógica das rochas (grau de vulnerabilidade ao intemperismo físico, químico e biológico); a caracterização das formações superficiais; e o condicionamento estrutural das rochas (fraturas; dobras e falhas).

- a Geomorfologia, por sua vez, deve ser analisada de acordo com: a gênese das formas do relevo; o grau de dissecação do relevo; a amplitude de relevo; a geometria das vertentes e topos; a declividade; e a vulnerabilidade frente aos processos erosivo-deposicionais (Dantas et al. 2008).

- a Pedologia deve ser analisada de acordo com:

3 Compreende-se aqui como "Geossistema", sua concepção mais completa desenvolvida por Bertrand (1972), onde a paisagem geográfica consistiria de um tripé que envolvia uma análise integrada de fatores abióticos, bióticos e antrópicos, conforme já discutido anteriormente. 
a gênese dos solos e processos pedogenéticos (classes de solos); química dos solos (fertilidade); física dos solos (profundidade, textura, densidade, condições de drenagem, erodibilidade); morfologia dos solos (estrutura e arranjo das partículas) e aptidão ou capacidade de uso das terras.

- a Hidrologia e a Climatologia devem ser analisadas de acordo com: a dinâmica atmosférica regional (classificação climática); a distribuição espacial da pluviosidade e temperatura; o balanço hídrico; a infiltração e o escoamento da água no solo; a água subterrânea.

Após a percepção das inter-relações entre as diversas componentes e condicionantes acima citados (Figs. 2, 3 e 4), os procedimentos técnicos adotados para o mapeamento da Geodiversidade consistiu de uma sequência de ações como: levantamento e compilação de dados, análise temática (compartimentação geológica e de relevo), consolidação dos dados, sínteses inter-temáticas, geração e análise de dados complementares (atividade de campo), correlação das variáveis, síntese integrativa e geração das unidades da geodiversidade.

Em escalas continentais (1:2.500.000 ou 1:1.000.000), os mapeamentos de geodiversidade devem se resumir a uma mega-compartimentação geológica ou geológico-geomorfológica dos grandes conjuntos de paisagens do meio físico. Em escalas regionais $(1: 100.000 \mathrm{a}$ 1:250.000), os mapeamentos de geodiversidade devem, forçosamente, ser acrescidos de informações pedológicas, hidrológicas e climatológicas, apesar de estas informações já estarem contidas na macroescala (1:1.000.000) como variáveis de análise interet al. (2014) -temática, ainda não representadas espacialmente, como a compartimentação de relevo. Em escalas de detalhe (maiores que 1:50.000), a metodologia de mapeamento é similar, contudo, a quantidade de feições mapeáveis será cada vez maior, na medida em que a escala de mapeamento e as bases temáticas tornam-se mais detalhadas.

Os resultados alcançados no Brasil baseados na incorporação da variável ambiental ao processo de ordenação territorial e a incorporação da sustentabi-

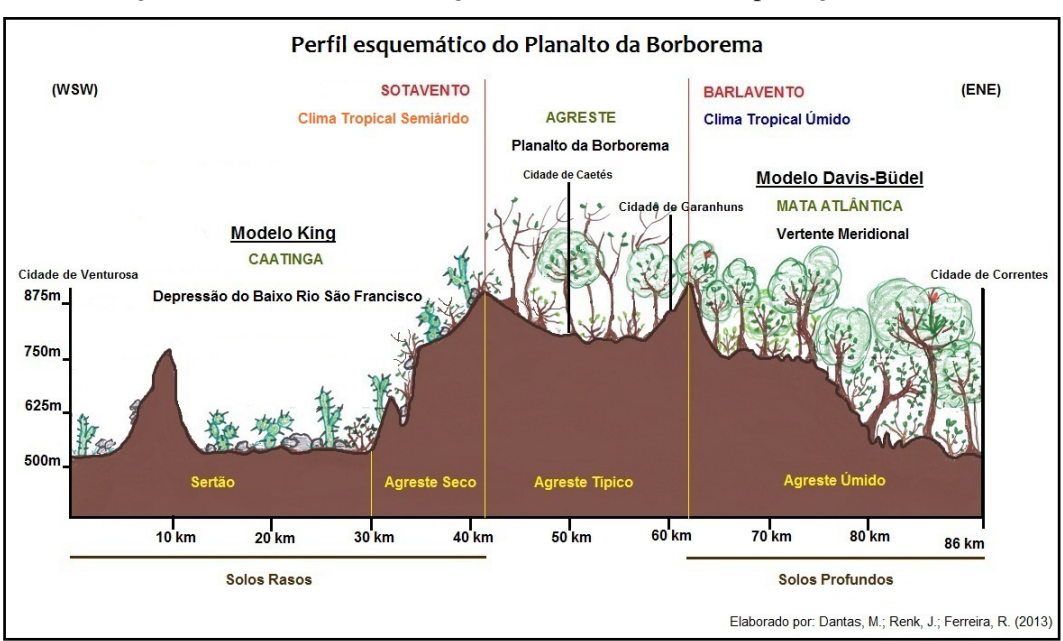

Figura 2. Perfil esquemático entre as cidades de Correntes e Venturosa, em Pernambuco. Transição entre o agreste úmido, com vegetação de Mata Atlântica, para o sertão semiárido, com vegetação de caatinga, onde os processos morfogenéticos estão diretamente relacionados com o efeito orográfico promovido pelo Planalto da Borborema. Fonte: Ferreira et al. (2013)

\section{Configuração Geoecológica do Planalto Dissecado Gurupi-Grajaú}

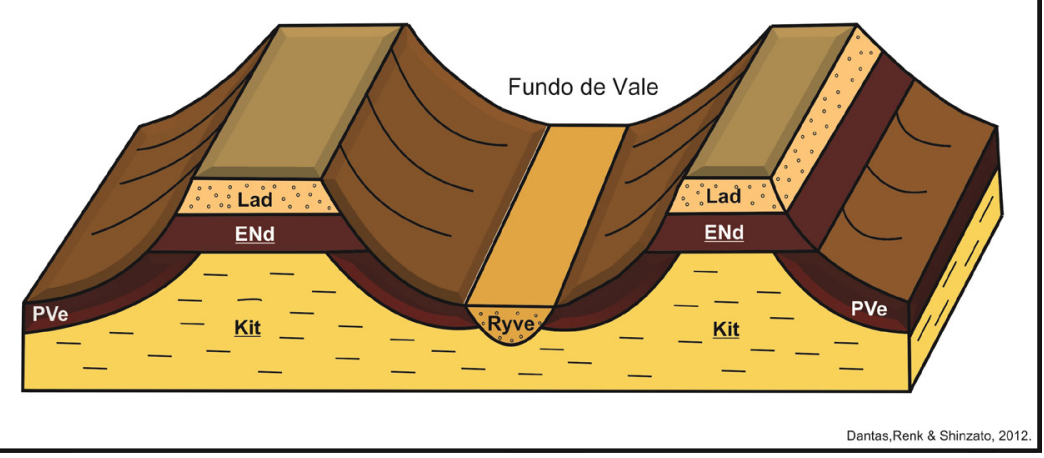

Figura 3. Modelo esquemático da configuração geoecológica do Planalto Dissecado Gurupi-Grajaú, no Maranhão, embasado por arenitos arcoseanos de idade cretácica da formação Itapecuru (Kit): Topos de platôs sustentados por crostas lateríticas $(E N d)$ e o desenvolvimento de solos profundos e bem drenados Latossolos Amarelos distróficos (LAd). Intensa dissecação em vales entalhados, exibindo vertentes declivosas e processos de erosão, em área de solos menos espessos - Argissolos Vermelhos eutróficos (PVe). Fundos de vale apresentam expressiva sedimentação aluvionar e solos de boa fertilidade natural, com predomínio de Neossolos Flúvicos eutróficos e vérticos (RYve). Fonte: Dantas 


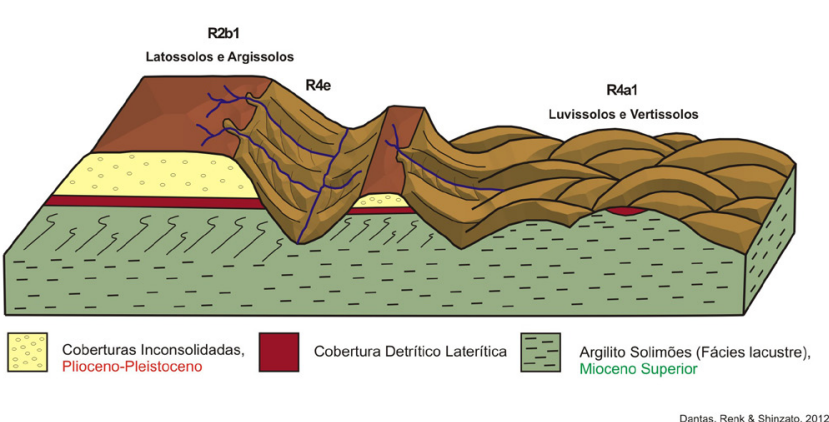

Figura 4. Modelo esquemático da configuração geoecológica do Leste do Acre. As superfícies mais elevadas são representadas pelos baixos platôs lateríticos (R2b1) que atestam uma antiga superfície de aplainamento Plio-Pleistocênica, sendo sustentada por crostas e coberturas detrítico-lateríticas. Desenvolvem-se solos profundos, bem drenados e lixiviados (Latossolos e Argissolos). Esses baixos platôs são bruscamente delimitados por rebordos erosivos (R4e) de 30 a 50 metros de desnivelamento. Com a denudação, recuo erosivo e remoção do pacote sedimentar dos baixos platôs lateríticos, são exumados os argilitos esmectíticos, siltitos e arenitos finos das fácies lacustre ou fluviodeltaica da Formação Solimões. Essas litologias são esculpidas num relevo de colinas amplas (R4a1) com o desenvolvimento de solos pouco profundos e boa fertilidade natural (Luvissolos e Vertissolos). Fonte: Dantas et al. (2014).

lidade ambiental aos modelos de desenvolvimento valorizou a concepção de ambiente com uma especial preocupação em produzir um mapeamento do meio físico que não seja desarticulado da realidade sócio-econômica.

Todavia, tais estudos, por vezes, abordam a dinâmica sócio-econômica no contexto da questão ambiental de forma superficial denominando-a, genericamente, de "fator antrópico", fato este bastante comum em obras produzidas por geólogos ou "geógrafos físicos".

No "reverso da medalha", a mesma crítica pode ser aplicada aos mapeamentos de infraestrutura e logística executados por "geógrafos humanos" assentados em uma base cartográfica em branco, abstraindo-se por completo das informações do meio físico (assemelhando-se com o conceito de espaço topológico engendrado pelos geógrafos neopositivistas).

\section{Considerações Finais}

A análise integrada da paisagem constitui um dos instrumentos metodológicos mais relevantes para os estudos de geodiversidade. O Mapa de Geodiversidade do Brasil desenvolvido pela CPRM nas escalas de 1:2.500.000 e 1:1.000.000 visa, portanto, associar o substrato do meio físico (uma compartimentação geológico-geomorfológica do território brasileiro) que consistiu na delimitação das grandes unidades de paisagem naturais (ou geossistemas articulados) a um conjunto distinto de aspectos, dentre os quais, destacam-se:

1. zonas de interesse especial para estudos de Geodiversidade (áreas de arenização e desertificação; riscos geológicos; disponibilidade hídrica; obras civis; disposição de resíduos sólidos; áreas de interesse para Geoturismo e Geoconservação)

2. zonas de restrição legal (áreas de preservação ambiental; terras indígenas; terras quilombolas) e

3. um conjunto de intervenções econômicas (rede urbana; malha viária; malha de gasodutos e oleodutos; rede de linhas de transmissão elétrica; áreas de produção mineral nos seus diversos segmentos; arranjos produtivos locais do setor mineral) que consistiram nos elementos humanos das paisagens geográficas (Silva et al. 2008b).

A identificação e a caracterização da estrutura espacial fornecem um referencial técnico que possibilita a incorporação da variável do meio físico ao processo de ordenamento do território. A estrutura espacial é representada por unidades territoriais, sendo calcada em primeiro plano na geologia e geomorfologia seguida de contribuições temáticas afins. Desta forma, o Mapa de Geodiversidade consiste, efetivamente, num instrumento de grande aplicabilidade para a Gestão Ambiental e para o Planejamento Territorial.

Em síntese, a paisagem natural ou a paisagem geomorfológica é uma fração da paisagem geográfica e, portanto, o objeto de estudo, por excelência, dos estudos de Geodiversidade.

\section{Referências}

Bennett M.R., Doyle P. 1997. Environmental Geology: Geology and the Human Environment. New York: John Wiley \& Sons. 512p.

Bertrand G. 1972. Paisagem e Geografia Física Global: ensaio metodológico. São Paulo. Inst. Geografia/USP. Cadernos de Ciências da Terra, 13:1-27.

Brilha J. 2005. Patrimônio Geológico e Geoconservação: a conservação da natureza na sua vertente geológica. Braga, Portugal: Palimage Eds. 190p.

Claudino-Sales V. 2010. Paisagens geomorfológicas espetaculares: geomorfossítios do Brasil. Reci- 
fe: Revista de Geografia, 3:6-20.

Coelho Netto A.L. 1992. O Geoecossistema da Floresta da Tijuca. In: Abreu M.A. Ed. 1992. Natureza e Sociedade no Rio de Janeiro. Rio de Janeiro, Secr. Mun. Cultura/DGDI, Biblioteca Carioca, 21:104-142.

Cordani U. 2002. The role of the Earth Sciences in a sustainable world. Episodes, 23(3):155-162.

Correa P.R.S., Ramos V.L.S. 1995. Diagnóstico Geoambiental. In: Rocha A.J.D. org. Projeto Mapas Municipais. Município de Morro do Chapéu (BA). CPRM Serviço Geológico do Brasil, Salvador, p. 148-155.

Corrêa R.L. 1995. Espaço: um conceito-chave da Geografia In: Castro I.E. Gomes P.C. Corrêa R.L. orgs. 1995. Geografia: conceitos e temas. Rio de Janeiro, Ed. Bertrand Brasil, p. 15-47.

CPRM - Serviço Geológico do Brasil. 1994. Mapa Geoambiental de Morro do Chapéu, BA: escala 1:200.000, Relatório e Mapa + CD-ROM. Brasília: CPRM - Serviço Geológico do Brasil.

CPRM - Serviço Geológico do Brasil. 2007. Mapa de Geodiversidade do Brasil: escala 1:2.500.000, Legenda Expandida + CD-ROM. Brasília: CPRM - Serviço Geológico do Brasil. 68p.

Dantas M.E., Coelho Netto A.L. 1995. O impacto do ciclo cafeeiro na evolução da paisagem geomorfológica do Médio Vale do Rio Paraíba do Sul. IBGE, Cadernos de Geociências, 15:65-72.

Dantas M.E., Shinzato E., Medina A.I., Silva C.R., Pimentel J., Carvalho Jr. A., Lumbreras J.F., Calderano S. 2005. Diagnóstico Geoambiental do Estado do Rio de Janeiro. In: CYTED - Oficina Internacional de. Ordenamento Territorial Mineiro. CPRM - Serviço Geológico do Brasil. URL: http://www.cprm.gov.br/publique/media/ artigo_geoambientalRJ.pdf. Acesso: 13.04.2012.

Dantas M.E., Armesto R.C.G, Adamy A. 2008. A Origem das Paisagens. In: Silva C.R. Ed. 2008. Geodiversidade do Brasil: conhecer o passado para entender o presente e prever o futuro. Rio de Janeiro: CPRM - Serviço Geológico do Brasil, p. 33-56. (Cap. 3).

Dantas M.E., Shinzato E., Bandeira I.C.N., Souza L.V., Renk, J.F.C. 2013. Compartimentação geomorfológica do Estado do Maranhão. In: Bandeira I.C.N. Ed. 2013. Geodiversidade do Estado do Maranhão. Teresina: CPRM - Serviço Geológico do Brasil, p. 31-62. (Cap. 3).

Dantas M.E., Shinzato E., Adamy A., Bispo I., 2014. Origem das paisagens do Estado do Acre. In: Adamy A. Ed. 2014. Geodiversidade do Estado do Acre. Porto Velho: CPRM - Serviço Geológico do Brasil, p. 37-54. (Cap. 3).

Dorothy M. 1998. Environmental geology: an Earth System Science approach. New York: Freeman. 452p.

Duff K. 1994. Natural Areas: an holistic approach to conservation based on Geology. In: O'Halloran
D., Green C., Harley M., Stanley M., Knill J. eds. 1994. Geological and Landscape Conservation. London, Geol. Soc., p. 121-126.

Eberhard R. 1997. Pattern and Process: Towards a Regional Approach to National Estate Assessment of Geodiversity. Canberra: Australian Heritage Comm., Environ. Forest Taskforce, Environment Australia. (Technical Series 2).

Ferreira R.V., Dantas M.E., Shinzato E. 2013. Origem das paisagens do Estado de Pernambuco. In: Torres, F.M.S., Pfaltzgraff, P.A.S. Ed. 2013. Geodiversidade do Estado de Pernambuco. Recife: CPRM - Serviço Geológico do Brasil, p. 51-71. (Cap. 4).

Forman R.T.T. 1995. Land Mosaics: The Ecology of Landscapes and Regions. Cambridge, UK: Cambridge Univ. Press. 638p.

Gray M. 2004. Geodiversity: valuing and conserving abiotic nature. New York: John Wiley \& Sons. $434 p$.

Gray M. 2005. Geodiversity and geoconservation: what, why, and how? The George Wright Forum, 22(3):4-12.

Haesbaert R. 1998. Globalização e fragmentação do mundo contemporâneo. Niterói: EdUFF. 308p.

Keller E.A. 1996. Environmental Geology. New Jersey: Prentice-Hall. 562p.

Klink H.J. 1974. Geoecology and Natural Regionalization: basis for environmental research. Applied Sciences and Development, 4:48-74.

Kozlowski S. 2004. Geodiversity. The concept and scope of geodiversity. Przeglad Geologiczny, 52(8/2):833-837.

Lacoste Y. 1976. Geografia: isso serve, em primeiro lugar, para fazer a guerra. Campinas: Ed. Papirus. 263p.

Maia M.A.M., Marmos J.L. orgs. 2010. Geodiversidade do Estado do Amazonas. Manaus: CPRM - Serviço Geológico do Brasil 275p. URL: http://www. cprm.gov.br/publique/media/geodiversidade_ amazonas.pdf. Acesso 22.05.2012.

Maximiano L.A. 2004. Considerações sobre o conceito de Paisagem. UFPR. RA'E GA, O Espaço Geográfico em Análise, 8:83-91

Monteiro C.A.F. 2001. Geossistemas: a História de uma Procura. São Paulo: Ed. Contexto. 127p. (/ GEOUSP Abordagens).

Monbeig P. 1984. Pioneiros e fazendeiros em São Paulo. São Paulo: Ed. Hucitec, 369p.

Moraes A.C.R. 1984. Geografia: pequena história crítica. São Paulo: Ed. Hucitec. 138p.

Panizza M. 2001. Geomorphosites: concepts, methods and examples of geomorphological survey. Chinese Sci. Bull., 46(Suppl.):4-6.

Penha H.M. 1994. Processos endógenos de formação do relevo. In: Guerra A.J.T., Cunha S.B. orgs. 1994. Geomorfologia: Uma Atualização de Bases e Conceitos. Rio de Janeiro, Ed. Bertrand Brasil, 
p. 51-92.

Pereira A.R. 1995. Património geomorfológico no litoral sudoeste de Portugal. Finisterra, Revista Portuguesa de Geografia, 30(59-60):7-25.

Petrisor A.I., Sarbu C.N. 2010. Dynamics of geodiversity and eco-diversity in territorial systems. Journal of Urban and Regional Analysis, 2(1):61-70.

Press F., Siever, R., Grotzinger J., Jordan T.H. 2006. Para Entender a Terra. Trad.: Menegat R., Fernandes P.C.D., Fernandes L.A.D., Porcher C.C. 4 ed. Porto Alegre: Bookman. 656 p.

Rodriguez J., Silva E.V. 2002. A classificação das paisagens a partir de uma visão geossistêmica. Mercator, Revista do Depto. de Geografia-UFC. 1(1): 98-115.

Rougerie G. 1971. Geografia das Paisagens. São Paulo: Ed. DIFEL. 134p.

Salgueiro T.B. 2001. Paisagem e Geografia. Finisterra: Revista Portuguesa de Geografia, 36(72):37-53.

Santos M. 2000. Por uma outra globalização: do Pensamento Único à Consciência Universal. Rio de Janeiro: Ed. Record, 174p.

Serrano E., Ruiz-Flaño P. 2007. Geodiversity. A theoretical and applied concept. Geographica Helvetica, 62(3):140-147.

Sharples C. 1993. A methodology for the identification of significant landforms and geological sites for conservation purposes. Report to forestry commission, Tasmania. URL: http://eprints.utas.edu.au/11747/. Acesso 08.11.2011.

Sharples C. 2002 Concepts and Principles of Geoconservation. Tasmanian Parks \& Wildlife Service. Austrália, 79p.

Silva C.R., Ramos M.A.B., Pedreira A.J., Dantas M.E. 2008a. Começo de Tudo. In: Silva C.R. ed. 2008. Geodiversidade do Brasil: conhecer o passado para entender o presente e prever o futuro. CPRM Serviço Geológico do Brasil, Rio de Janeiro, p. 11-20. (Cap. 1).

Silva C.R., Marques V.J., Dantas M.E., Shinzato E. 2008b. Aplicações múltiplas do conhecimen- to da Geodiversidade. In: Silva C.R. ed. 2008. Geodiversidade do Brasil: conhecer o passado para entender o presente e prever o futuro. Rio de Janeiro, CPRM - Serviço Geológico do Brasil. p. 181-202. (Cap. 13).

Silva C.R., Dantas M.E. 2010. Mapas Geoambientais In: Simpósio Brasileiro de Cartografia Geotécnica e Geoambiental, 7, Maringá/PR. ABGE, 17 p. URL:

$<$ http://www.cprm.gov.br/publique/media/mapas geoambientais_SCGG.pdf>. Acesso 08.11.2011.

Sauer C. 1998 A morfologia da Paisagem. In: Corrêa R.L., Rosendahl Z. orgs. 1998. Paisagem, Tempo e Cultura. EdUERJ, Rio de Janeiro. p. 12-74.

Schier R.A. 2002. Trajetórias do conceito de Paisagem na Geografia. RA'E GA - O Espaço Geográfico em Análise - UFPR, 7:79-85

Selby M.J. 1985. Earth's Changing Surface. Oxford, UK: Clarendon Press. 607p.

Sotchava V. 1960. O Estudo dos Geossistemas. Inst. Geografia/USP. Métodos em Questão, 16:1-51.

Stanley M. 2001. Welcome to the $21^{\text {st }}$ century, Geodiversity Update, 1:1-8.

Tricart J. 1977. Ecodinâmica. Rio de Janeiro: IBGE, Rec. Nat. e Meio Amb. 91p.

Troll C. 1966. Landscape Ecology. ITC-UNESCO Centre for Integrated Surveys, Paper S. 4. 23p.

Veiga A.T.C. 1999. A geodiversidade e o uso dos recursos minerais da Amazônia. Terra das Águas UnB, 1: 88-102.

Xavier da Silva J., Carvalho Filho L.M. 2001. Índice de Geodiversidade da Restinga da Marambaia (RJ): um exemplo do geoprocessamento aplicado à Geografia Física. Recife: Revista de Geografia, 1:57-64.

Zonneveld I.S. 1989. The Land Unit - a fundamental concept in Landscape Ecology, and its applications. Landscape Ecology, 3:67-86.

RESUMO: A Geodiversidade consiste num novo campo de conhecimento derivado da geologia ambiental que visa proceder a uma abordagem abrangente do sistema abiótico envolvendo uma análise articulada e dinâmica entre rochas, formações superficiais, relevo e solos. 0 desenvolvimento de pesquisas em geodiversidade, a partir da década de 1990, gerou resultados promissores em geoconservação e gestão territorial no Brasil e no mundo. Todavia, é necessário consolidar o conceito de paisagem, tão arraigado na ciência geográfica, aos estudos de geodiversidade, para que haja um fortalecimento metodológico de tais estudos em base multidisciplinar. Este artigo visa uma avaliação epistemológica do conceito de paisagem e de sua importância teórica e metodológica para os estudos de geologia ambiental e geodiversidade, advindo da experiência acumulada pela CPRM - Serviço Geológico do Brasil, em sua missão de mapear a Geodiversidade de todo o território brasileiro.

PALAVRAS-CHAVE: Geodiversidade, Análise da Paisagem, Geologia Ambiental, Epistemologia. 